\title{
2006: A stellar year for financing
}

Stacy Lawrence

Last year, biotech excelled in terms of financing, but failed to set the stock markets alight. Total biotech financing surpassed 2000 levels to reach $\$ 46$ billion, although much of this came from partnership deals

\section{Stock market performance}

Mainstream indices closed strongly to finish the year with double-digit increases, whereas biotech indices had no gains or some losses after recovering in the third quarter.

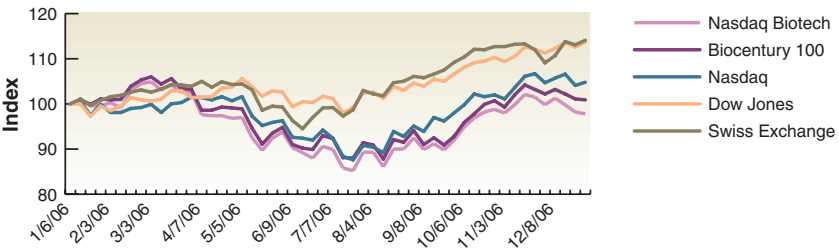

All indices reset to 100 at start of year for better visualization of annual trend. Source: Multex, BioCentury

\section{Global biotech initial public offerings}

Markets in Europe continued to account for a significant share of IPO funds raised, with those in Asia-Pacific also contributing.

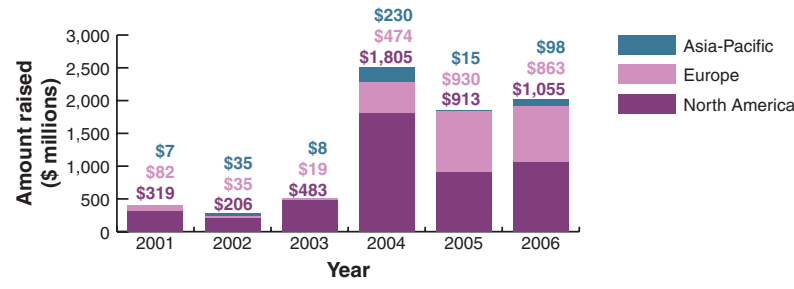

Source: BioCentury

Notable 2006 biotech deals

\begin{tabular}{|c|c|c|c|c|}
\hline \multirow{6}{*}{ IPOs } & $\begin{array}{l}\text { Company } \\
\text { (Lead underwriters) }\end{array}$ & $\begin{array}{c}\text { Amount } \\
\text { raised } \\
(\$ \text { millions })\end{array}$ & $\begin{array}{l}\text { Percent change in } \\
\text { stock price } \\
\text { since offer }\end{array}$ & $\begin{array}{c}\text { Date } \\
\text { launched }\end{array}$ \\
\hline & $\begin{array}{l}\text { Altus Pharmaceuticals } \\
\text { (Merrill Lynch., Morgan Stanley, } \\
\text { SG Cowen) }\end{array}$ & 105.0 & $26 \%$ & $1 / 26 / 06$ \\
\hline & Renovo (Goldman Sachs) & 99.9 & $101 \%$ & $7 / 4 / 06$ \\
\hline & $\begin{array}{l}\text { Newron Pharmaceuticals } \\
\text { (Lehman Brothers, } \\
\text { Morgan Stanley) }\end{array}$ & 99.0 & $-3 \%$ & $12 / 8 / 06$ \\
\hline & Affymax (Morgan Stanley) & 92.5 & $38 \%$ & $12 / 14 / 06$ \\
\hline & $\begin{array}{l}\text { Wilex (WestLB, Sal. } \\
\text { Oppenheim ir. \& Cie) }\end{array}$ & 70.2 & $1 \%$ & $11 / 10 / 06$ \\
\hline \multirow[t]{6}{*}{$\begin{array}{l}\text { Venture } \\
\text { capital }\end{array}$} & $\begin{array}{l}\text { Company } \\
\text { (Lead investors) }\end{array}$ & $\begin{array}{c}\text { Amount } \\
\text { invested } \\
(\$ \text { millions })\end{array}$ & $\begin{array}{l}\text { Number } \\
\text { of round }\end{array}$ & Date closed \\
\hline & $\begin{array}{l}\text { Kalypsys } \\
\text { (Tavistock Life Sciences) }\end{array}$ & 100.0 & 3 & $11 / 29 / 06$ \\
\hline & $\begin{array}{l}\text { Macroflux } \\
\text { (Nomura Phase4 Ventures) }\end{array}$ & 75.0 & 1 & 10/10/06 \\
\hline & $\begin{array}{l}\text { Microbia } \\
\text { (Sigma Capital Management) }\end{array}$ & 75.0 & 5 & 2/27/06 \\
\hline & Xanthus Pharmaceuticals (N/A) & 68.0 & 2 & $11 / 30 / 06$ \\
\hline & $\begin{array}{l}\text { Merrimack Pharmaceuticals } \\
(\mathrm{N} / \mathrm{A}) \text {. }\end{array}$ & 65.0 & 5 & $4 / 3 / 06$ \\
\hline \multirow[t]{8}{*}{$\begin{array}{l}\text { Mergers \& } \\
\text { acquisitions }\end{array}$} & Acquirer/target & $\begin{array}{l}\text { Deal value } \\
\text { (\$ millions) }\end{array}$ & $\begin{array}{c}\text { Date } \\
\text { announced }^{2}\end{array}$ & \\
\hline & Merck/Serono & 13,200 & $9 / 6 / 06$ & \\
\hline & $\begin{array}{l}\text { Abbott Laboratories/Kos } \\
\text { Pharmaceuticals }\end{array}$ & 3,700 & $11 / 6 / 06$ & \\
\hline & Gilead Sciences/Myogen & 3,200 & $10 / 6 / 06$ & \\
\hline & Eli Lilly/lcos & 2,300 & $10 / 6 / 06$ & \\
\hline & Watson Pharmaceuticals/Andrx & 1,900 & $3 / 6 / 06$ & \\
\hline & $\begin{array}{l}\text { AstraZeneca/Cambridge Antibody } \\
\text { Technology }\end{array}$ & 1,100 & $5 / 6 / 06$ & \\
\hline & Merck/Sirna Therapeutics & 1,100 & $10 / 6 / 06$ & \\
\hline
\end{tabular}

where payments may (or may not) extend into the future. Debt deals led all categories, almost doubling over 2005, whereas private investment in public equity (PIPEs) increased by more than half.

\section{Global biotech industry financing}

Biotech financing increased by $24 \%$ to $\$ 47$ billion, with the amount of debt raised almost doubling and PIPEs growing by more than half. Partnering, venture capital and public offerings also grew, albeit more modestly.

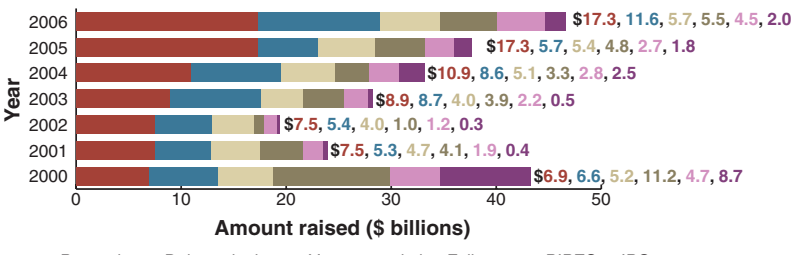

Source: BioCentury, Burrill \& Company

\section{Global biotech venture capital investment}

VC investment climbed by $5 \%$ making this the third year in a row of growth.

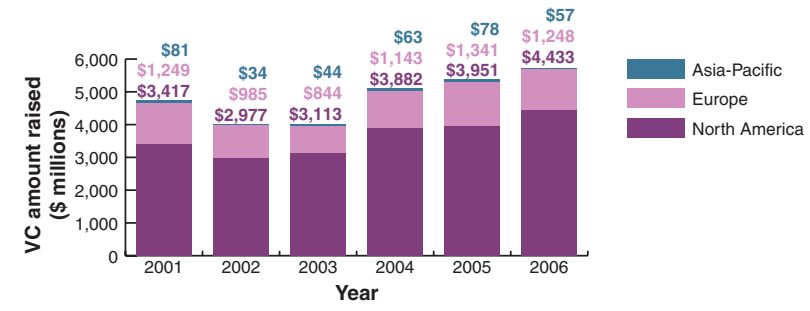

Source: BioCentury

\begin{tabular}{|c|c|c|c|c|}
\hline \multirow[t]{8}{*}{$\begin{array}{l}\text { Licensing/ } \\
\text { collaboration }\end{array}$} & Researcher/investor & $\begin{array}{c}\text { Value } \\
\text { (\$ millions) }\end{array}$ & $\begin{array}{l}\text { Deal } \\
\text { description }\end{array}$ & Date \\
\hline & Genmab/GlaxoSmithKline & 2,100 & $\begin{array}{l}\text { Develop of } \\
\text { atumumab } \\
\text { (anti-CD20 } \operatorname{lgG} 1 \kappa \text { ) }\end{array}$ & $12 / 19 / 06$ \\
\hline & ChemoCentryx/GlaxoSmithKline & 1,500 & $\begin{array}{l}\text { Develop four } \\
\text { anti-inflammatory } \\
\text { small molecules } \\
\text { targeting CCR1/ } \\
\text { CCR9/C5aR }\end{array}$ & $8 / 24 / 06$ \\
\hline & $\begin{array}{l}\text { Epix Pharmaceuticals/ } \\
\text { GlaxoSmithKline }\end{array}$ & 1,200 & $\begin{array}{l}\text { Develop small } \\
\text { molecules targeting } \\
\text { G protein-coupled } \\
\text { receptors }\end{array}$ & $12 / 13 / 06$ \\
\hline & Fibrogen/Astellas & 815 & $\begin{array}{l}\text { License small } \\
\text { molecules inhibiting } \\
\text { hypoxia-inducible } \\
\text { factor prolyl } \\
\text { hydroxylase }\end{array}$ & $4 / 28 / 06$ \\
\hline & Trubion/Wyeth & 800 & $\begin{array}{l}\text { Develop single-chain } \\
\text { polypeptides } \\
\text { targeting CD20 }\end{array}$ & $1 / 3 / 06$ \\
\hline & Plexxikon/Roche & 706 & $\begin{array}{l}\text { Develop small } \\
\text { molecule targeting } \\
\text { B-RafV600E gene }\end{array}$ & $10 / 5 / 06$ \\
\hline & $\begin{array}{l}\text { Sirna Therapeutics/ } \\
\text { GlaxoSmithKline }\end{array}$ & 700 & $\begin{array}{l}\text { Develop RNAi drugs } \\
\text { for respiratory disease }\end{array}$ & $4 / 3 / 06$ \\
\hline
\end{tabular}

${ }^{1}$ As of January $3 .{ }^{2}$ As of deal announcement date. Source: BioCentury, Recombinant Capital 